\title{
Extramural extension of a buried over-the-scope clip in the stomach: an unusual adverse event
}

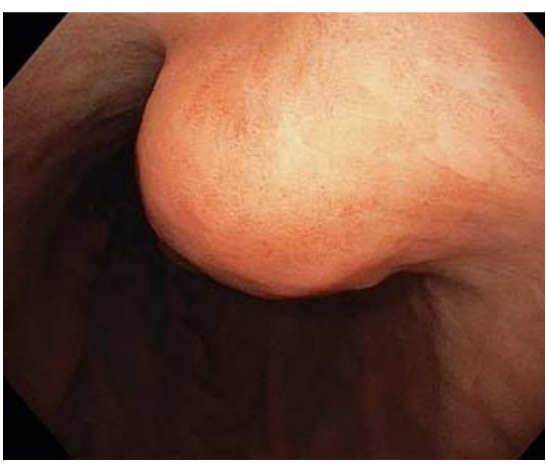

- Fig. 1 Endoscopic view of the gastrointestinal stromal tumor of the gastric body.

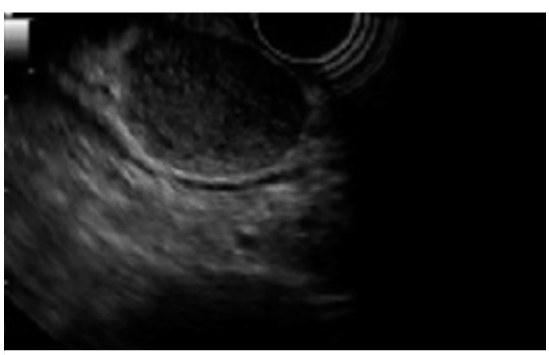

Fig. 2 Echoendoscopic view of the gastrointestinal stromal tumor.

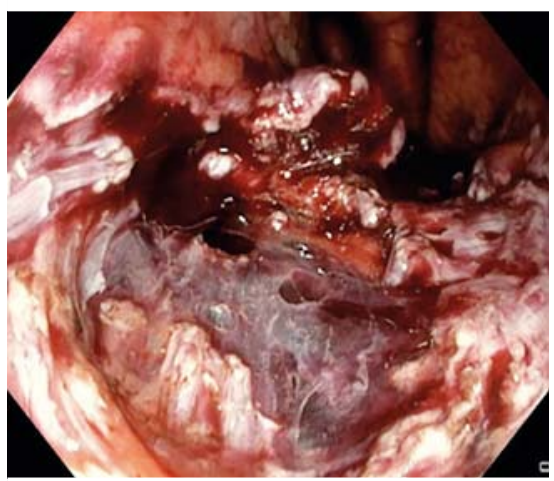

Fig. 3 Full-thickness defect in the gastric wall following enucleation of gastrointestinal stromal tumor.

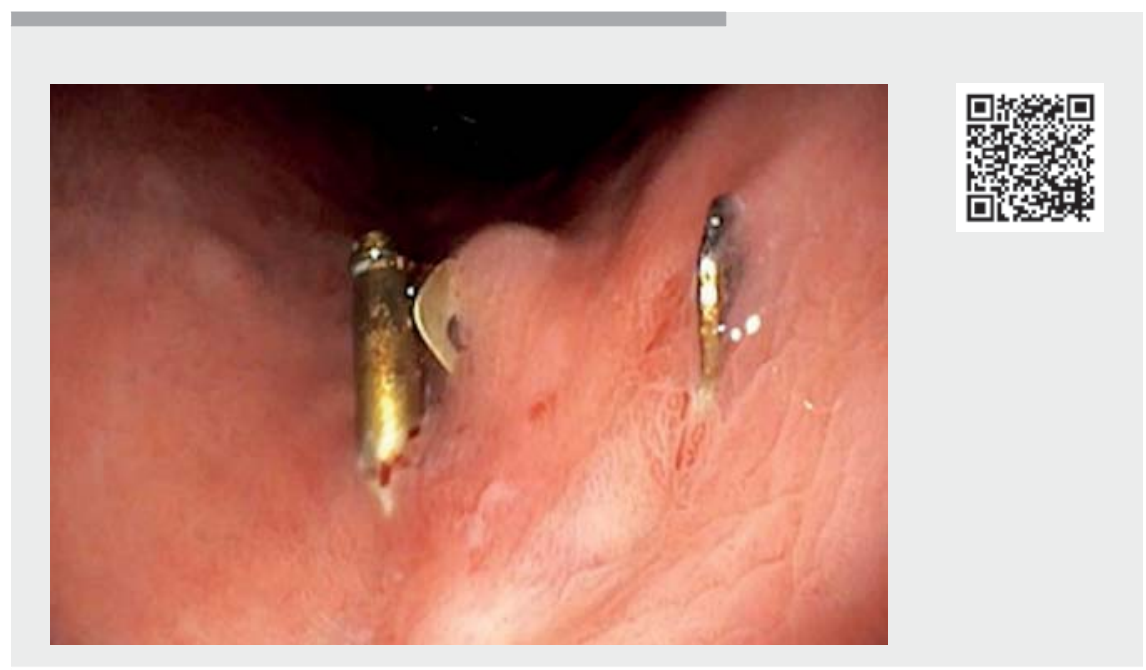

Video 1 Enucleation of a 25-mm gastrointestinal stromal tumor (GIST) located in the gastric body and sealing of the full-thickness defect in the gastric wall with an over-thescope clip (OTSC). At 6-month follow-up gastroscopy and CT scan, the buried OTSC with prominent extramural extension was seen.

An 82-year-old woman with a 25-mm gastrointestinal stromal tumor (GIST) in the gastric body ( $>$ Fig. 1, $>$ Fig. 2 ) underwent curative endoscopic submucosal enucleation. As the lesion originated deep within the gastric wall, a 15-mm full-thickness defect occurred ( $>$ Fig.3). The defect was completely sealed with the omental patch technique using one over-the scope clip (OTSC) (11/6t; Ovesco Endoscopy, Tuebingen, Germany) and six through-the-scope clips (Meditalia, Italy) (> Fig.4). The patient remained asymptomatic after the procedure and was discharged home 2 days later.

A 6-month follow-up gastroscopy showed no recurrence of the GIST. However, the OTSC was found to be completely embedded within the gastric wall ( Video 1). A computed tomography (CT) scan confirmed the transmural location of the OTSC and also showed its prominent extramural extension ( $\vee$ Fig.5).

The OTSC is a safe device with great efficacy in the treatment of acute gastrointestinal bleeding, perforations, leaks, and fistulas [1]. A recent systematic re- view analyzing $>1500$ cases in which an OTSC was used showed a $1.7 \%$ overall OTSC-related complication rate, with severe complications, mainly hemorrhage, stenosis, and perforation, occurring in $0.59 \%$ of cases. However, a buried OTSC was not mentioned [2]. Another systematic review reported the buried OTSC as a very rare adverse event that is the main cause of failure of endoscopic OTSC removal [3]. Currently, there are no previous reports of a buried OTSC with an extramural extension.

In the case described here, the buried OTSC may eventually leak out of the gastric wall and need surgery to be removed. In order to prevent this, endoscopic removal of the OTSC, although challenging, could be attempted. However, we pursued a conservative approach, as the patient remained asymptomatic, and her age and comorbidities represented significant risk factors for surgery should a complication occur during endoscopic OTSC removal.

Endoscopy_UCTN_Code_CPL_1AH_2AK 


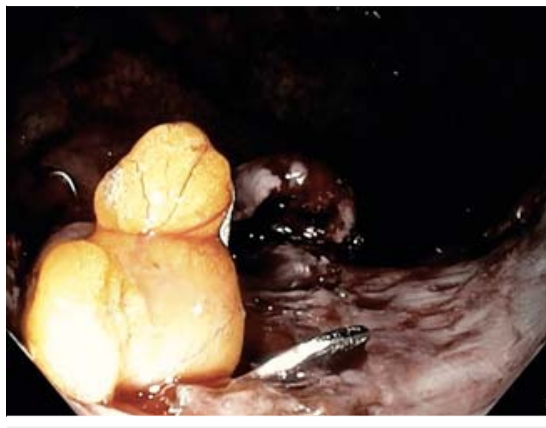

- Fig. 4 Sealed gastric wall defect with the omental patch technique using an over-the-scope clip.

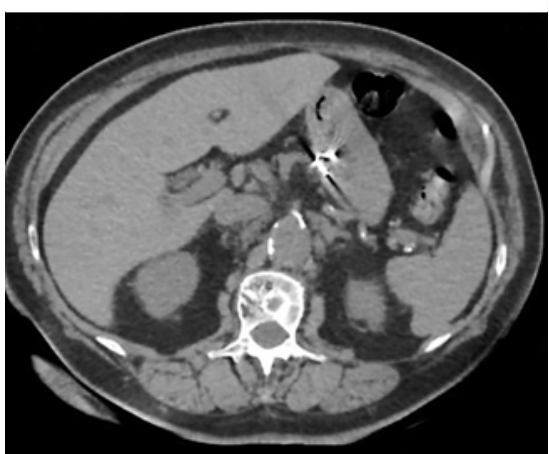

Fig. 5 Computed tomography scan image showing transmural location of the over-the-scope clip with prominent extramural extension.

\section{Competing interests}

The authors declare that they have no conflict of interest.

The authors

Giuliano Francesco Bonura, Paola Soriani, Paolo Biancheri, Tommaso Gabbani, Mauro Manno

Gastroenterology and Digestive Endoscopy Unit, Azienda USL Modena, Carpi, Italy

\section{Corresponding author}

\section{Mauro Manno, MD}

Gastroenterology and Digestive Endoscopy Unit, Azienda USL Modena, Via Guido

Molinari 2, Carpi 41012, Italy

m.manno@ausl.mo.it

\section{References}

[1] Chandrasekar VT, Desai M, Aziz M et al. Efficacy and safety of over-the-scope clips for gastrointestinal bleeding: a systematic review and meta-analysis. Endoscopy 2019; 51: 941-949

[2] Kobara H, Mori H, Nishiyama N et al. Overthe-scope clip system: a review of 1517 cases over 9 years. J Gastroenterol Hepatol 2019; 34: 22-30

[3] Ou YH, Kong WS, Li LF et al. Methods for endoscopic removal of over-the-scope clip: a systematic review. Can I Gastroenterol Hepatol 2020; 23: 5716981
Bibliography

Endoscopy 2022; 54: E486-E487

DOI 10.1055/a-1630-5676

ISSN 0013-726X

published online 8.10.2021

(C) 2021. Thieme. All rights reserved.

Georg Thieme Verlag KG, Rüdigerstraße 14, 70469 Stuttgart, Germany

\section{ENDOSCOPY E-VIDEOS}

https://eref.thieme.de/e-videos

口回 Endoscopy E-Videos is an open access online section, 靣艘: reporting on interesting cases and new techniques in gastroenterological endoscopy. All papers include a high quality video and all contributions are freely accessible online. Processing charges apply (currently EUR 375), discounts and wavers acc. to HINARI are available.

This section has its own submission website at

https://mc.manuscriptcentral.com/e-videos 